\title{
THE UPTAKE AND EXCRETION OF NITROUS OXIDE IN THE NEWBORN
}

\section{D.J. Steward and R.E. Creighton}

THE UPTAKE of nitrous oxide $\left(\mathrm{N}_{2} \mathrm{O}\right)$ into the alveolus in children has been described by Salanitre and Rackow' ${ }^{\prime}$ and is found to be more rapid than occurs in adults. This is ascribed to the increased cardiac output, greater alveolar ventilation and larger proportion of vessel rich tissues in infants and children. Salanitre and Rackow ${ }^{2}$ also measured nitrous oxide volumes absorbed and excreted during nitrous oxide anaesthesia with controlled ventilation in infants and young children. We could not find any previous reports of nitrous oxide uptake and excretion during spontaneous ventilation in the newborn.

\section{METHOD}

The rate of rise of alveolar levels of nitrous oxide during induction of anaesthesia with 70 per cent concentrations of nitrous oxide and the rate of decline in these levels during recovery was studied in a series of newborns weighing 2.7 to 3.5 $\mathrm{kg}$. Alveolar concentrations were measured by means of a fine catheter at the tip of the tracheal tube, through which gases were continuously sampled and then analysed by mass spectrometry. During each of the first four minutes of recovery the expired gases were collected in latex bags and analysed. The total volume for each minute was measured using a super syringe and the volume of nitrous oxide calculated by subtraction of the determined concentrations of oxygen (using a Servo Mex Analyser), carbon dioxide (using a Haldane Apparatus) and water vapour (calculated by assuming that expired gases are saturated at room temperature).

\section{RESULTS}

Figure 1 shows the rate at which endexpiratory levels of nitrous oxide approached in-

D.J. Steward, M.B., F.R.C.P.(C), and R.E. Creighton, M.D., F.R.C.P. (C). Department of Anaesthesia, The Hospital for Sick Children, and University of Toronto, Toronto, Ontario, Canada.

Address requests for reprints to: Dr. D.J. Steward, Chief of Anaesthesia, The Hospital for Sick Children, 555 University Avenue, Toronto, Ontario, Canada, M5G IX8.

Canad. Anaesth. Soc. J., vol. 25, no. 3, May 1978 spired levels. A very steep initial curve is followed by a short second phase before the uptake curve assumes a horizontal position. The decline in alveolar levels of nitrous oxide after its administration was stopped is shown in Figure 2.

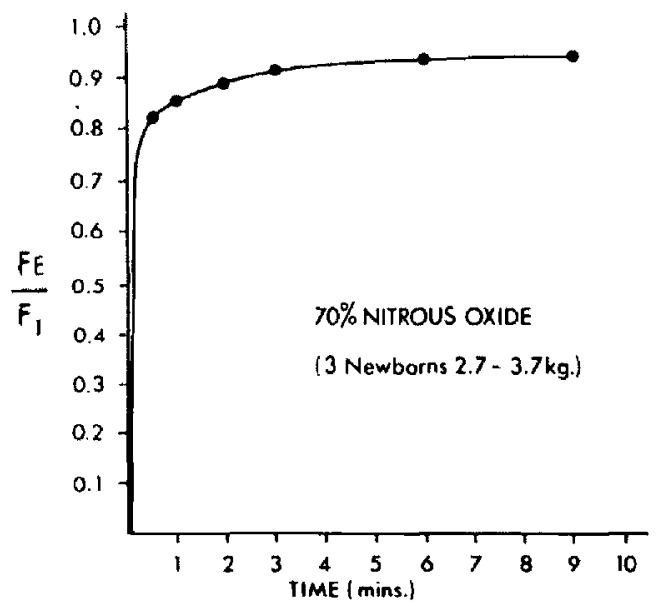

Figure 1. Ratio of end-expired to inspired concentration of nitrous oxide during induction of anaesthe sia.

\section{PERCENT ALVEOLAR $\mathrm{N}_{2} \mathrm{O}$}

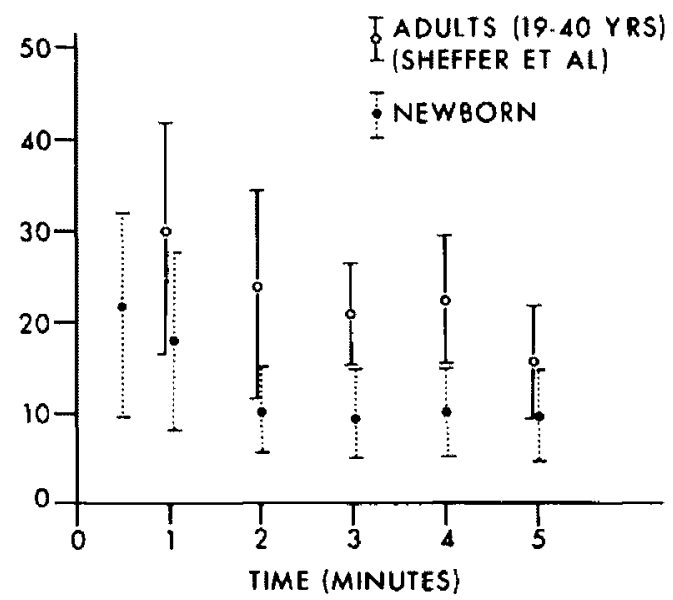

FIGURE 2. End-expiratory nitrous oxide concentrations during recovery. Percentage alveolar $\mathrm{N}_{2} \mathrm{O}$ calculated in adults is shown for comparison. 
For comparison, similar data measured in a series of adults by Sheffer, et al. ${ }^{3}$ (1972) are included. In the newborn the alveolar level rapidly falls to 10 per cent within two minutes, while in the adult this concentration is not reached until 10 minutes.

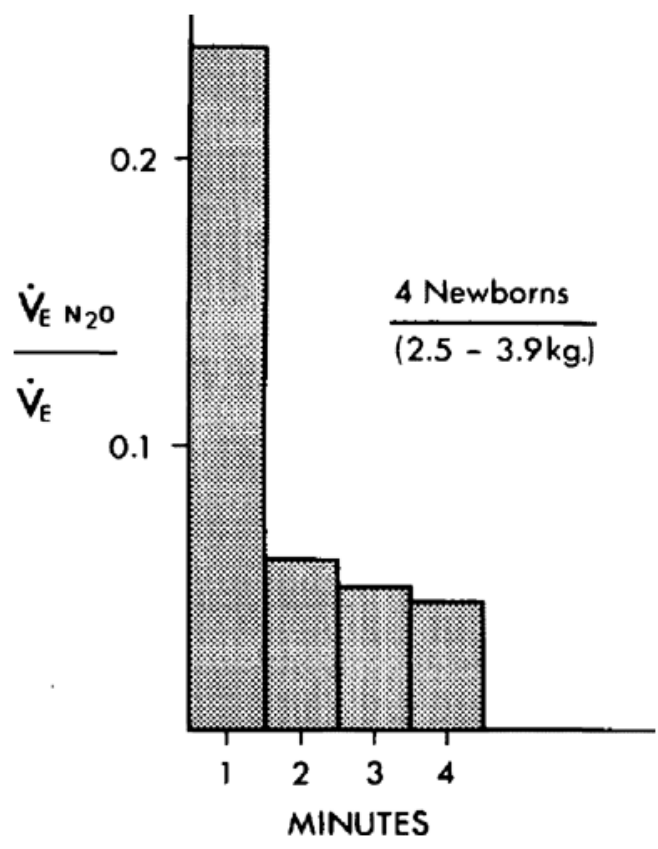

Figure 3. Ratio volumes of nitrous oxide in expired gases related to total expired minute volumes during recovery.

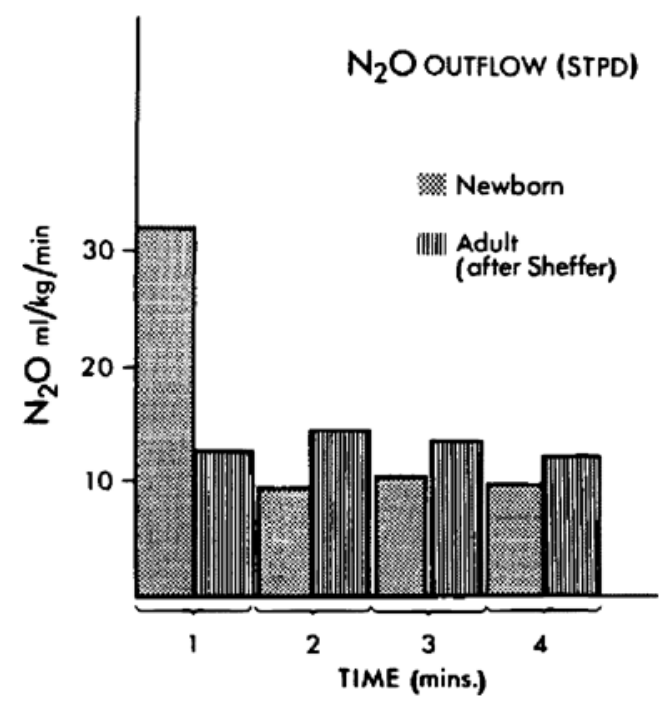

FIGURE 4. Volumes of nitrous oxide expired related to body weight in infants and adults.
Figure 3 shows the volumes of nitrous oxide expired compared to the total expired minute volumes during each minute after discontinuing the agent. Although in the first minute the expired gases contained 24 per cent nitrous oxide, this percentage falls to six per cent by the second minute. Figure 4 shows the volumes of expired nitrous oxide related to body weight in both infants and adults. The adult data were calculated from the results of Sheffer, et al. ${ }^{3}$ (1972).

\section{Discussion}

From a knowledge of the cardio-pulmonary physiology of the newborn, it could be predicted that uptake and elimination of an insoluble inhalation agent would differ considerably between the adult and the newborn. The ratio of the volume of alveolar ventilation to functional residual capacity is 5.0:1 in the infant compared to only $1.5: 1$ in the adult. This high ratio is responsible for the very rapid initial rise in alveolar concentration of the inspired gas and the equally rapid early decline in alveolar levels during recovery.

The factor which might be expected to oppose this rapid rise in alveolar levels is the high cardiac output of the newborn. Nitrous oxide, however, is a relatively insoluble agent, its blood/gas partition coefficient being only 0.47 ; thus the effect of cardiac output on the rate of rise in alveolar levels is minimized. In addition, the high cardiac output of the newborn is directed largely to vessel rich tissues, which comprise almost 20 per cent of the body mass in infants as compared with only 7 per cent in the adult. Vessel rich viscera have low tissue/blood partition coefficients for nitrous oxide and these tissues rapidly become saturated, at which point venous blood leaving these tissues retains high concentrations of nitrous oxide. High levels of nitrous oxide in venous blood returning to the lung from vessel rich tissues further diminishes the uptake of this agent from the alveolus.

The rapid outflow of large volumes of nitrous oxide within one minute of discontinuing the agent which is seen in the newborn is a consequence of the high proportion of vessel rich tissue, the high cardiac output, and large volume of alveolar ventilation. It is noted that despite the large volume of nitrous oxide excreted in the first minute, the level of this gas in the alveolus falls to levels below those measured in the adult by the end of one minute. 


\section{Summary}

In the newborn, the uptake of nitrous oxide into the alveolus is very rapid, as is the fall in alveolar levels following withdrawal of the agent.

During recovery relatively large volumes of nitrous oxide are excreted in the first minute, after which the excretion rate rapidly declines, most of the gas having been eliminated.

\section{RÉSUMÉ}

L'élévation de la concentration alvéolaire de protoxyde d'azote se fait très rapidement chez le nouveau-né. De même, les concentrations alvéolaires tombent très rapidement dès que l'on cesse son administration. On observe alors une élimination rapide de cet agent au cours de la première minute, puis la vitesse d'élimination tombe rapidement, la plus grande partie du protoxyde ayant été éliminée.

\section{REFERENCES}

1. Salanitre, E. \& Rackow, H. The pulmonary exchange of nitrous oxide and halothane in infants and children. Anesthesiology 30(4): 388-394 (1969).

2. Salanitre, E. \& Rackow, $\mathrm{H}, \mathrm{N}_{2} \mathrm{O}$ volumes absorbed and excreted during $\mathrm{N}_{2} \mathrm{O}$ anesthesia in children. Anesthesia and Analgesia, current researches. 55(1): 95-99 (1976)

3. Sheffer, L., Stefferson, J.L., \& Birch, A.A. Nitrous oxide-induced diffusion hypoxia in patients breathing spontaneously. Anesthesiology $37(4): 436-439$ (1972). 